\title{
$\mathrm{EV}$ 브레이크 경량화를 위한 하드아노다이징 부의 성능 평가

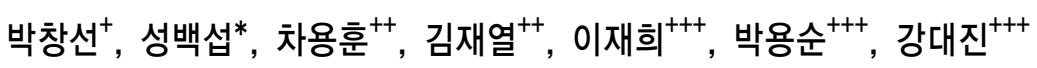 \\ (논문접수일 2011. 11. 17, 수정일 2011. 12. 29, 심사완료일 2012. 01. 12)
}

\section{Quality Evaluation of Hard Anodizing Zone for Lightness of the EV Brake Disks}

\author{
C. S. Park ${ }^{+}$, B. S. Sung*, Y. H. Cha ${ }^{++}$, J. Y. Kim ${ }^{++}$, J. H. Lee ${ }^{+++}$, Y. S. Park ${ }^{++}$, D. J. Kang ${ }^{+++}$
}

\begin{abstract}
This study evaluates the strength of surface treatment parts using the hard anodizing method to the aluminum alloy brake disks. In order to achieve weight reduction of vehicles, Eco-friendly cars parts of the high-quality and competitive price is to equip. Especially while pursuing parts of weight reduction, it has to maintain the strength of the surface of the brake by nature. To enhance surface strength of aluminum alloy, we use hard anodizing technology in the surface treatment. This study is resulted of 3 times greater the hardness value of the hard anodized specimen than the aluminum alloy specimen for the lightweight parts of EV brake disk
\end{abstract}

Key Words : Aluminum alloy(알루미늄합금), Brake disk(브레이크 디스크), Electric vehicle(EV, 전기자동차), Surface treatment(표면처리)

\section{1. 서 론}

전기자동차와 친환경 하이브리드 자동차 개발을 위한 관련된 최대의 관심기술은 연비 향상과 경량화 기술이다. 자동차 성능 향상을 위해서는 설계개선에 의한 방법과 소재의 경량화에 의 한 방법을 병행하여 추진하고 있고, 특히, 소재의 경량화 부품 은 전기자동차나 하이브리드 차의 경우에 주행거리의 증대 등 을 위하여 더욱 그 중요성이 커져 향후 자동차 기술의 핵심 개 발 대상이라 할 수 있다. 이러한 기술을 뒷받침하는 소재중 알 루미늄합금 소재를 많이 사용하고 있다 ${ }^{(1-3)}$.

전 세계 알루미늄의 용도별 사용량은 수송 분야가 대부분의 지역에서 가장 큰 수요를 차지하고 있다. 알루미늄은 경량성 뿐만 아니라 비강도, 내식성 및 열전도도 등이 우수하여 자동차
용 재료로 사용되면 최고 $40 \%$ 가량 경량화를 이룰 수 있으며, 종래 자동차 생산라인의 설비를 사용할 수 있다는 장점으로 자 동차 경량화를 위한 대체 재료로 주목받고 있다. 경량성 뿐만 아니라 $90 \%$ 이상 자원재활용이 가능한 알루미늄 합금은 급격 한 산업화로 인해 초래된 자원고갈과 환경오염이라는 측면에 서도 사용비율을 꾸준히 증가하였으며, 90 년대에는 $6 \sim 12 \%$ 로 증가하였고, 최근에는 사용비율이 $15 \%$ 이상으로 꾸준히 증가 하였다 ${ }^{(4-8)}$.

자동차용 브레이크 디스크의 소재로는 1950년대 디스크 로 터의 도입 이래 주로 회주철이 이용되어 왔다. 이러한 제품은 열전도성의 부족으로 브레이크 디스크가 반복 작동할 때 열균 열 등을 초래하며, 이 문제를 개선하기 위해 열확산 능력향상의 목적으로 소재조성의 조절, 주조방법의 개선, 벤트홀 구조의 변 
경 등이 사용 되고 있다. 그러나 브레이크디스크이 경량화를 위해서는 한계가 있으며, 일본, 미국, 독일 등에서는 알루미늄 합금 및 복합재료의 적용을 위하여 연구가 진행되고 있다. 알루 미늄은 낮은 밀도를 가지며 경량성, 부식에 대한 뛰어난 저항성 등의 특징을 가지고 있기 때문에 산업현장에서 그 수요가 증가 하고 있다. 하지만 경도가 낮고 표면이 손상되기 쉬우며, 높은 마찰특성을 가지므로 사용에 있어서 제한적이다 ${ }^{(9-11)}$.

이러한 한계를 극복하기 위해 적절한 표면처리가 필요하다. 표면 처리의 여러 가지 방법 중 하나인 아노다이징(anodizing) 은 양극 산화처리법을 이용하여 알루미늄의 표면에 산화 피막 이 형성하는 것으로 표면의 경도를 증가시키고 마멸과 부식에 대한 저항성을 증가시키는 것으로 알려져 있다.

따라서 본 논문에서는 $(\mathrm{H}) \mathrm{EV}$ 자동차의 초경량화를 이루기 위해서는 친환경자동차 부품의 품질향상과 가격경쟁력을 갖추 는데 있으며, 특히 부품의 경량화를 추구하면서 브레이크 특성 상 표면강도를 유지해야 함으로 표면처리 중에서 하드아노다 이징 기술을 이용하여 알루미늄합금의 표면강도를 높이고자 하였다. 하드아노다이징(anodizing)한 알루미늄 합금시험편에 경도시험과 마모시험을 통하여 시험편의 표면 사이의 마찰 및 마멸 특성을 평가하여 브레이크 디스크 제작에 있어서 적용 가 능성을 실험하였다.

\section{2. 하드아노다이징 처리}

하드아노다이징은 황산의 농도가 더 높고, 처리온도는 더 낮 으며, 전압과 전류밀도는 더 높다. 하드 피막은 상당히 단단하 고, 입자가 치밀하며, 내마모성이 우수하다. 치밀한 산화피막은 $-4^{\circ} \mathrm{C} \sim 0^{\circ} \mathrm{C}$ 의 저온에서 생성한다. 이 온도에서는 항산표준욕 에서 만큼 산화피막을 침식시키지 못한다. 저온에서 처리하므 로 사용전류밀도가 더 높아지고, 피막 기공이 적어지고 더욱 치밀해져서 피막이 강하게 되어 우수한 내마모성을 발휘한다. 하드아노다이징의 전류밀도는 일반적으로 $3 \mathrm{~A} / \mathrm{dm}^{2}$ 이고, 세 미하드 아노다이징은 $2 \mathrm{~A} / \mathrm{dm}^{2}$ 이며, 소프트 아노다이징은 $1 \mathrm{~A} / \mathrm{dm}^{2}$ 이다. 따라서 피막이 오르는 속도도 일반적으로 소프트 아노다 이징이 $1 \mathrm{~A} / \mathrm{dm}^{2}$ 시 3.6 분에 약 1 미크론 피막이 형성되고 세미 하드아노다이징은 $2 \mathrm{~A} / \mathrm{dm}^{2}$ 로 1.8 분에 약 1 미크론 오르고 하드 아노다이징은 $3 \mathrm{~A} / \mathrm{dm}^{2}$ 이므로 1.2 분에 약 1 미크론이 오른다. 하 드아노다이징은 산화피막의 생성속도가 빠르기 때문에 시주에 서 고속 하드아노다이징법이라고도 부른다.

하드아노다이징은 높은 전류밀도를 사용하기 때문에 교반이 중요하며 일반 아노다이징보다 래크의 단면적이 더 넓고, 접점 도 더 많아야 한다. 경질양극산화를 부품의 치수가 적을 때 재 생을 위한 처리로 사용하는데 이는 일반의 양극산화보다 피막 두께가 더 두껍기 때문이다. 하드아노다이징의 두께 범위는 2 에서 130 미크론 정도이다. 경질양극산화에서 얻을 수 있는 최
대 피막두께는 황산 전해액의 농도와 액온도에 따라 다르다. 황산농도가 높으면 높을수록 얻을 수 있는 최대의 피막두께는 얇다.

\section{3. 실 험}

\section{1 브레이크 디스크 문제점 분석}

Fig. 1과 같이 일반 승용차의 브레이크 시스템은 자동차의 안전성을 고려하여 설계 메카니즘이 복잡하고 이에 관련된 하 부 장치가 복잡하였다. 그러나 저속이면서 소형인 $\mathrm{EV}$ 전기자 동차 브레이크는 현재의 시스템과는 차별성을 두고 개발이 필 요하으로 본 논문에서는 경량화를 목표로 개발하는데 있어 브 레이크 디스크의 단순화 설계가 필요하였다.

Fig. 2에서와 같이 현재 주차브레이크 디스크의 무게는 차종 별로 다르나 대략 $10 \sim 18 \mathrm{~kg}$ 으로 조사 되었다. 그림에서와 같 이 주차 브레이크 디스크는 단순한 구조로 되어 있으며, 주물 형식인 덕타일 방식을 생산하기 때문에 제품의 무게가 무겁고 악조건의 외부 환경에 노출됨에 따라 부식현상이 이루어짐을 관찰 할 수 있었다.

\section{2 시험편}

$\mathrm{EV}$ 용 경량 디스크 브레이크를 개발하기 위하여 알루미늄 소 재 분석을 실시하였으며, Table 1과 Table 2는 화학적성질과 기계적성질을 보여주고 있다. 알루미늄합금으로 개발된 브레 이크 디스크의 앞면과 뒷면으로 브레이크 디스크 개발에 있어서 하드아노다이징 표면처리 작업을 하여 시험편을 제작하였다.
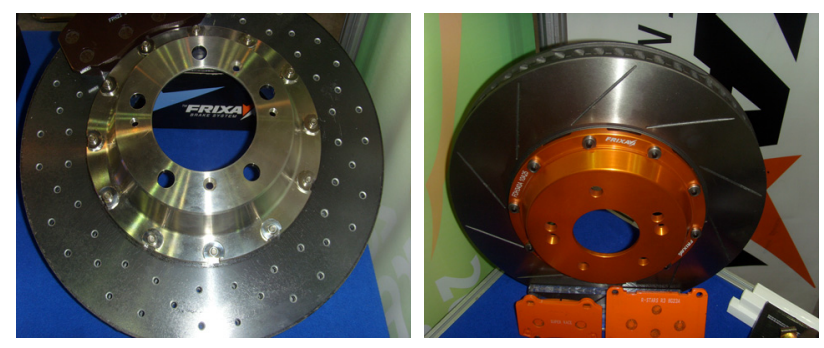

Fig. 1 High level brake disk

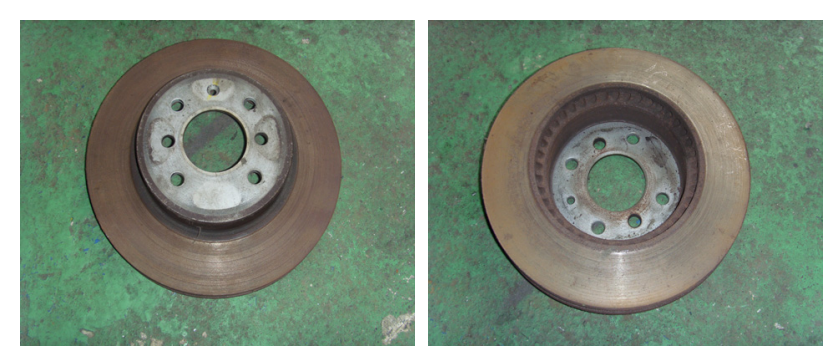

Fig. 2 Casting brake parts 
Table 1 Mechanical properties of aluminium alloys

\begin{tabular}{c|c|c|c|c}
\hline \hline $\begin{array}{c}\text { Tensile } \\
\text { strength } \\
\left(\mathrm{N} / \mathrm{mm}^{2}\right)\end{array}$ & $\begin{array}{c}\text { Elongation } \\
\%\end{array}$ & $\begin{array}{c}\text { Coefficient of } \\
\text { thermal } \\
\text { expansion } \\
\left({ }^{\circ} \mathrm{C}\right)\end{array}$ & $\begin{array}{c}\text { Specific } \\
\text { gravity } \\
\left(20^{\circ} \mathrm{C}\right)\end{array}$ & $\begin{array}{c}\text { Temperature } \\
\text { conduction } \\
\left(25^{\circ} \mathrm{C}\right)\end{array}$ \\
\hline 310 & 12 & 21 & 2.76 & 0.26 \\
\hline $\begin{array}{c}\text { Melting } \\
\text { area } \\
\left({ }^{\circ} \mathrm{C}\right)\end{array}$ & $\begin{array}{c}\text { Diecasting } \\
\text { temp. } \\
\left({ }^{\circ} \mathrm{C}\right)\end{array}$ & $\begin{array}{c}\text { Solidification } \\
\text { start temp. } \\
\left({ }^{\circ} \mathrm{C}\right)\end{array}$ & $\begin{array}{c}\text { Electric conduction } \\
(\%)\end{array}$ \\
\hline $625 \sim 655$ & $635 \sim 680$ & 582 & \multicolumn{2}{|c}{27} \\
\hline
\end{tabular}

Table 2 Chemical compositions of Al alloy

\begin{tabular}{c|c|c|c|c|c|c|c|c}
\hline \hline $\mathrm{Cu}$ & $\mathrm{Si}$ & $\mathrm{Mg}$ & $\mathrm{Zn}$ & $\mathrm{Fe}$ & $\mathrm{Mn}$ & $\mathrm{Ti}$ & $\mathrm{Cr}$ & $\mathrm{Al}$ \\
\hline 0.15 & $0.4 \sim$ & 0.8 & 0.25 & 0.7 & 0.15 & 0.15 & $0.04 \sim$ & balance \\
$\sim 0.4$ & 0.8 & $\sim 1.2$ & less & less & less & less & 0.35 & \\
\hline
\end{tabular}

Table 3 Hard anodizing experiment conditions for specimen

\begin{tabular}{c|c|c|c|c}
\hline \hline spec. & $\begin{array}{c}\text { Voltage } \\
(\mathrm{V})\end{array}$ & $\begin{array}{c}\text { Current } \\
\text { density } \\
\left(\mathrm{A} / \mathrm{dm}^{2}\right)\end{array}$ & $\begin{array}{c}\text { Time } \\
(\mathrm{min})\end{array}$ & $\begin{array}{c}\text { Temp. } \\
\left({ }^{\circ} \mathrm{C}\right)\end{array}$ \\
\hline SPA & 15 & 3 & 70 & 0 \\
\hline SPB & 15 & 3 & 70 & -4 \\
\hline
\end{tabular}

Table 3은 하드아노다이징 실험조건을 위해 황산 $25 \%$, 전압 $15 \mathrm{~V}, 0.01 \mathrm{~m}^{2}$ 당 $3 \mathrm{~A} / \mathrm{dm}^{2}$ 의 전류를 흘려 제작하였다. 같은 실험 조건에서 온도를 $\mathrm{SPA}\left(-4^{\circ} \mathrm{C}\right)$ 와 $\mathrm{SPB}\left(-1^{\circ} \mathrm{C}\right)$ 의 두 개의 시험조건 으로 제작된 시험편을 마모실험과 경도시험을 위하여 시편을



(a) disk front

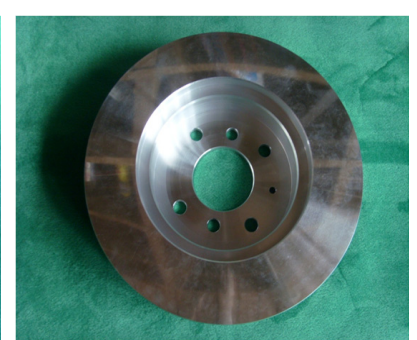

(b) disk back
Fig. 3 Brake disk to the aluminum alloy

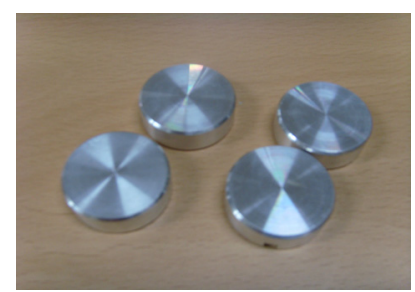

(a) No treatment

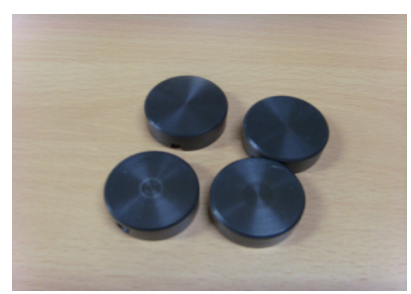

(b) Hard anodizing
Fig. 4 Specimens for experiment test

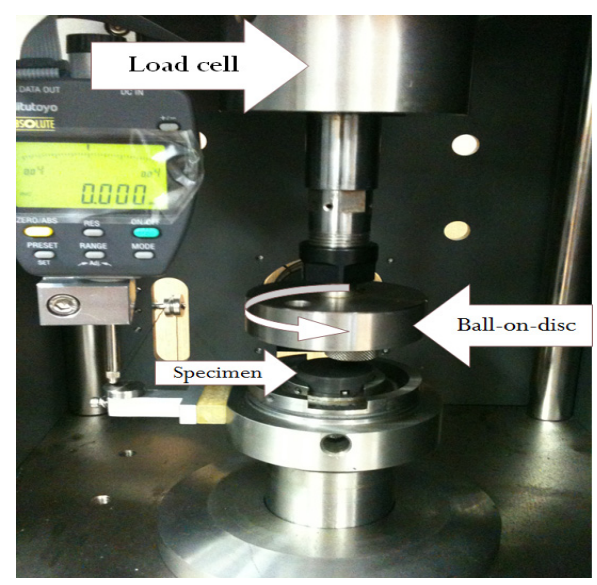

Fig. 5 The picture of Ball-on-disc type sliding wear tester

제작하였다. 아노다이징 된 시편의 표면 거칠기는 $0.9 \mu \mathrm{m}(\mathrm{Ra})$ 이다.

Fig. 5에서와 같이 모제 시편과 아노다이징 표면 처리된 시험 편의 마찰 및 마멸 특성을 평가하기 위하여 마모시험을 실시하 였다. 실험에 사용한 시험기는 Ball-on-disc 타입으로 하였다. 실험 환경은 건 마찰 환경(Dry condition)이고, 시험속도는 $50 \mathrm{rpm}(0.12 \mathrm{~m} / \mathrm{s})$, 하중 $1 \mathrm{~kg}$ 으로 $100 \mathrm{sec}$ 씩 총 시험편 15 개씩 시험을 실시하였다.

\section{4. 결과 및 고찰}

\section{1 마모시험 분석}

Fig. 6은 모제시편의 평균마찰계수이며, 실험 시 시간별 변위 를 측정하여 실험의 공정성을 확보하고자 하였으며, 실험을 실 시하였다. 실험결과 모재 시험편에서 마찰계수가 0.55 으로 측 정 되었다. Fig. 7은 하드 아노다이징한 시편으로 평균마찰계 수가 0.4 로 표면처리 하지 않는 시편보다 낮은 마찰계수를 가 짐을 알 수가 있다. 실험결과 하드 아노다이징 실험조건에 따른 마찰계수는 차이가 나타나지 않았다. 측정된 마찰계수는 일반 주물용 브레이크 디스크와 별 차이가 없었으며, 전기자동차에 적용 가능함을 알 수 있었다.

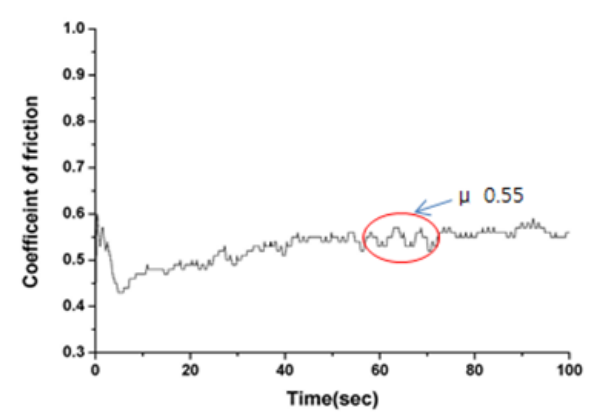

Fig. 6 Coefficient of friction for No treatment 


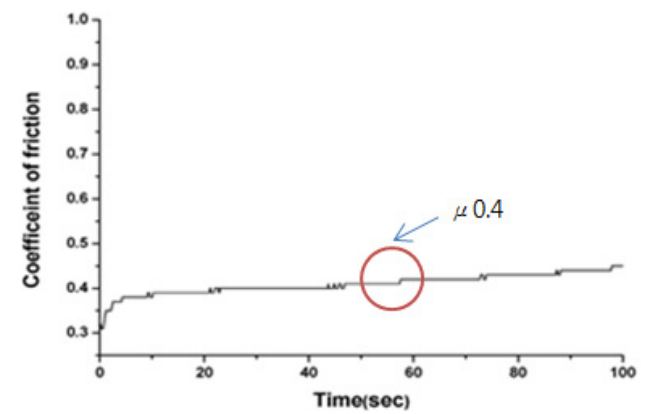

Fig. 7 Coefficient of friction for Hard anodizing

\section{2 경도시험 및 표면 두께분석}

표면의 경도를 측정하기 위하여 마이크로 비커스 실험을 실 시하였으며, 본 실험에 사용한 알루미늄 합금 재질과 아노다이 징 시험편을 합금소재와 비교하여 비커스 경도를 비교 분석하 였다.

하드아노다이징 처리에 의해 얻은 피막성질은 재질의 제조방 법, 성분조성 및 금속조직 등 재질적 요인과 전해액의 종류, 농 도, 온도, 전류밀도 및 두께 등의 전해조건과 후처리조건에 따 라 크게 영향을 받는다. 경도시험을 위하여 다량의 시험편을 제작하고 그중에서 엄선된 시험편 3개씩을 선택하여 실험을 실 시하였다. Fig. 8은 알루미늄합금의 경도시험 결과이며, Fig. 9

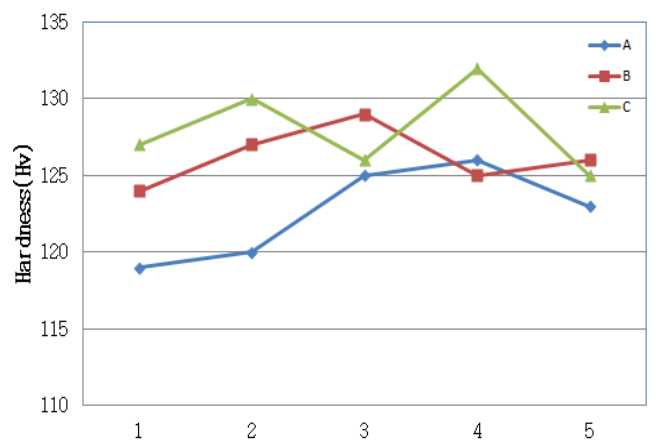

Fig. 8 Hardness test results of aluminum alloy (Hv)

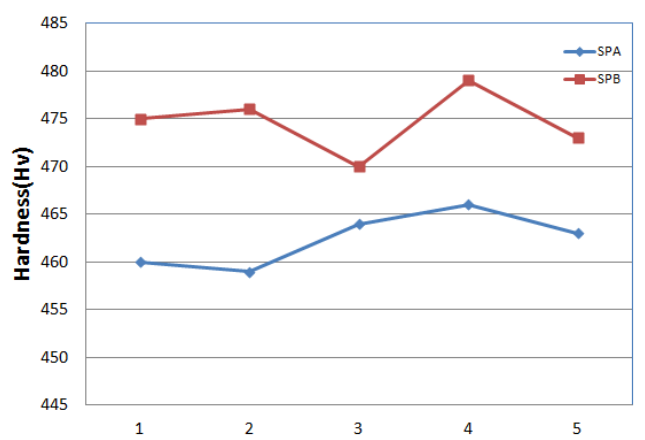

Fig. 9 Results of hard anodizing on $-4^{\circ} \mathrm{C}$ and $0^{\circ} \mathrm{C}$

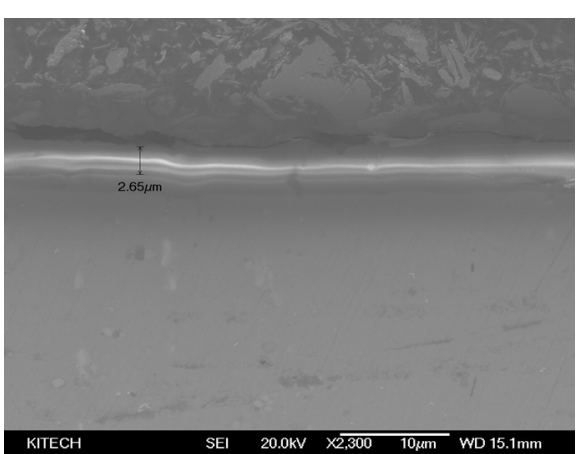

(a) Surface thickness in the $0^{\circ} \mathrm{C}$

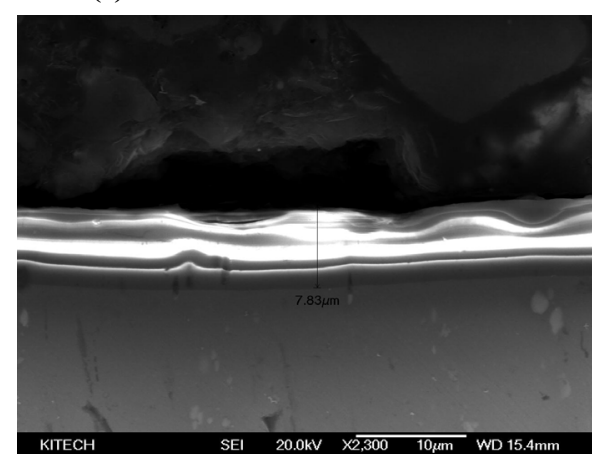

(b) Surface thickness in the $-4^{\circ} \mathrm{C}$

Fig. 10 SEM results in the Hard anodizing $0^{\circ} \mathrm{C}$ and $-4^{\circ} \mathrm{C}$

에서와 같이 알루미늄합금 모재보다 하드아노다이징 부의 경 도값이 3.5 4배 이상의 향상된 결과 값을 관찰하였다.

실험 분석결과 온도가 저온일수록 하드아노다이징 표면 두께 가 치밀해지며, Fig. 10 의 SEM 사진 관찰결과 하드아노다이징 처리온도 $0^{\circ} \mathrm{C}$ 보다 $-4^{\circ} \mathrm{C}$ 의 실험조건에서 $2.65 \mu \mathrm{m}$ 에서 $7.83 \mu \mathrm{m}$ 두꺼워지는 결과를 얻었다.

\section{5. 결 론}

고강도 초경량 브레이크 개발을 위하여 디스크 표면처리를 실시하였으며, 마모시험 및 경도시험을 통하여 브레이크 하드 아노다이징 부의 성능을 측정하였다.

그 결과 하드아노다이징 표면처리된 시험편에서 평균 마찰계 수는 $0.40 \sim 0.45$ 정도 측정되었다. 이것은 하중 증가에 따라 마 찰계수는 증가 하였으며, 모재의 시험편보다 하드아노다이징 표면처리된 시험편에서 마찰계수가 현재 상용화 된 브레이크 디스크의 마찰계수에 근접하게 측정되어 전기자동차 경량화를 위하여 응용이 가능하리라 판단된다. 또한, 하드아노다이징 온 도를 $-4^{\circ} \mathrm{C}$ 와 $0^{\circ} \mathrm{C}$ 일 때 디스크 표면의 차이점을 분석하기 위하 여 경도시험을 실시한 결과 알루미늄 합금 모재 시험편 보다 하드아노다이징된 시험편에서 경도값이 3.5 4배 이상의 결과 값을 얻었다. 이러한 결과로 저온일수록 하드아노다이징 표면 의 조직이 치밀하고, 표면 두께가 두꺼워짐을 예측할 수 있었다. 


\section{참 고 문 헌}

(1) Sustainability of the European aluminium industry 2006, the European Aluminium Association (EAA).

(2) Kim, E. S., Lee, K. H., and Moon, Y. H., 2000, “A Feasibility sStudy of the Partial Squeeze and Vacuum Die Casting Process", Journal of Materials Processing Technology, Vol. 105, No. 1, pp. 42 48.

(3) El-Mahallawy N, A., Taha, M. A., Pokora, E., and Klein, F., 1998, “On the Influence of Process Variables on the Thermal Conditions and Properties of High Pressure Die-cast Magnesium Alloys," J. of Mat. Science and Tech. Vol. 73, No. 1, pp. 125 138.

(4) Lu, S. C., Rebello, A. B., Miller, R. A., Kinzel, G. L., and Yagel, R. Y., 1997, “A Simple Visualization Tool to Support Concurrent Engineering Design," Computer Aided Design, Vol. 29, No. 10, pp. 727 735.

(5) Zhang, W., Xiong, S., and Liu, B., 1997, "Study on a CAD/CAE System of Die Casting," J. of Mat. Science and Tech. Vol. 63, No. 3, pp. 707 711.

(6) Rizzo, A., Signore, M. A., Pemza, M., Tagliente, M. A., Riccardis, F. D., and Serra, E., 2006, "Sputter Deposition of Semicrystalline Thin Dioxide Films," Thin Solid Films, Vol. 520, No. 6, pp. 2554 2561.

(7) Bhushan, B., 1999, Principles and Applications of Tribology, Wiley-Interscience Pub, USA, pp. 896 929

(8) ASTM, 2009, Anodic Oxide Coatings on Aluminum, ASTM B580:2009, American Society of Testing Materials, USA.

(9) Wernick, S., Pinner, R., and Sheasby, P. G., 1987, The Surface Treatment and Finishing of Aluminium and Its Alloys, ASM International, Finishing Publications Ltd. USA.

(10) Sheasby, P. G., and Brace, A. W., 1976, The technology of anodizing aluminium, Technicopy Limited, Australia.

(11) Hackensack, N. J., 1998, Metal Finishing. Guidebook and Directory Issues, Elsevier Science Inc. USA, pp. 395 412. 